\title{
Oxidative Decarboxylation and Deamination of Essential Amino Acids by Nicotinium Dichromate - a Kinetic Study
}

\author{
K. Vivekanandan, R. Lakshmi Narayanan* \\ PG and Research Department of Chemistry, National College (Autonomous), \\ Tiruchirappalli - 620 001, Tamil Nadu, India \\ "E-mail address: rInarayanan.che@gmail.com
}

\begin{abstract}
The oxidation of essential amino acids like valine, leucine, isoleucine, threonine, phenylalanine and histidine using nicotinium dichromate in aqueous medium in presence of perchloric acid at $313 \mathrm{~K}$ leads to the formation of corresponding aldehydes. The reaction is first order with respect to nicotinium dichromate, fractional order with respect to amino acids and second order with respect to perchloric acid. Increase in ionic strength by the addition of sodium perchlorate has no effect on the rate constant. There is no polymerization with acrylonitrile. The reaction has been studied at different temperatures and a mechanism confirming to the kinetic observations is suggested.
\end{abstract}

Keywords: Oxidation; Kinetics; essential amino acids; Nictotinium dichromate

\section{INTRODUCTION}

Chromium compounds have been used in aqueous and non-aqueous medium for the oxidation of organic compounds. Chromium compounds especially $\mathrm{Cr}$ (VI) reagents have been versatile reagents and capable of oxidizing almost all the oxidizable organic functional moieties [1]. The development of chromium (VI) reagents for the oxidation of organic substrates continues to be of interest. A number of chromium (VI) containing compounds [2-15] have been used to study the kinetics and mechanism of various organic compounds. Nicotinum Dichromate (NDC) is a stable, non-hygroscopic, mild, efficient and selective oxidizing reagent in synthetic organic chemistry. A review of literature shows that the kinetic studies using this reagent are meager [16-18]. Human body is made up of protein. Protein plays a crucial role in almost all biological processes and amino acids are the building blocks of it. They play a role in the transport and the storage of nutrients. Amino acids have an influence on the function of organs, glands, tendons and arteries. They are further more essential for healing wounds and repairing tissue, especially in the muscles, bones, skin and hair as well as for the removal of all kinds of waste deposits produced in connection with the metabolism. If the body is lacking in the minimum energy and nutrients, the body cannot carry out its bodily and mental functions. Without the necessary vitamins, proteins (amino acids), trace elements and minerals, there is a risk of debilities and metabolic disorders which can have serious consequences. The kinetics and mechanism of oxidation of essential amino acids by various oxidants have been reported [19-24]. However, the kinetics of oxidation of essential amino acids by nicotinium dichromate has not yet been studied. In the present work, 
the results on the kinetics of oxidation of essential amino acids by nicotinium dichromate in aqueous medium in presence of perchloric acid are reported and a probable mechanism is suggested.

\section{EXPERIMENTAL METHODS}

\subsection{Reagents}

All the essential amino acids like valine, leucine, isoleucine, threonine, phenylalanine and histidine (LOBA) were of accepted grades of purity. All other reagents were of analytical grade. The ionic strength of the system was maintained at a constant value using sodium perchlorate. Solution of amino acids were prepared in doubly distilled water and these solutions were employed for kinetic studies.

\subsection{Preparation of Nicotinium Dichromate (NDC)}

Chromium trioxide $(4.8 \mathrm{~g})$ was dissolved in water $(4.8 \mathrm{ml})$ and then nicotinic acid $(2.9$ g) was added at $0-5{ }^{\circ} \mathrm{C}$ (ice-water bath) with mechanical stirring. After $15 \mathrm{~min}$, acetone (10 ml) was added at $0-5{ }^{\circ} \mathrm{C}$ to the resulting red-orange suspension and the mixture was stirred at $0-5{ }^{\circ} \mathrm{C}$ for $15 \mathrm{~min}$. The product was filtered off and washed with acetone $(80 \mathrm{ml})$ and dichloromethane $(10 \mathrm{ml})$, affording nicotinium dichromate as on orange yellow solid. Standard iodometric procedure was adopted in estimating nicotinium dichromate [25], m.pt. $214-216{ }^{\circ} \mathrm{C}$, yield $65 \%$.

\subsection{Kinetic measurements}

The pseudo-first order conditions were maintained by a large excess of the substrate over nicotinium dichromate. The reaction was initiated by mixing a calculated amount of thermostated nicotinium dichromate into the reaction mixture. The kinetic measurements were carried out spectrophotometrically in a thermostated cell compartment of a spectrophotometer at $470 \mathrm{~nm}$. The kinetics run were followed upto $60 \%$ completion of the reaction. The pseudofirst order rate constants were evaluates from the linear $(r=0.990-0.999)$ plots of $\log$ [absorbance] versus time by the least square method and were reproducible within $\pm 3 \%$.

\subsection{Stoichiometry and product analysis}

The aldehyde formed as the oxidation product were determined by the reported method [26]. The stoichiometric analysis showed that one mole of amino acid consumed by one mole of the oxidant.

$$
\mathrm{RCH}\left(\mathrm{NH}_{2}\right) \mathrm{COOH}+\mathrm{Cr}(\mathrm{VI})+\mathrm{H}^{+} \longrightarrow \mathrm{RCHO}+\mathrm{CO}_{2}+\mathrm{NH}_{3}+\mathrm{Cr}(\mathrm{IV})
$$

Here

$$
\begin{gathered}
\mathrm{R}=\left(\mathrm{CH}_{3}\right)_{2} \mathrm{CH},\left(\mathrm{CH}_{3}\right)_{2} \mathrm{CH}-\mathrm{CH}_{2}, \mathrm{CH}_{3}-\mathrm{CH}_{2}-\mathrm{CH}, \mathrm{CH}_{3} \mathrm{CH}(\mathrm{OH}), \mathrm{C}_{6} \mathrm{H}_{5}-\mathrm{CH}_{2}, \\
\text { and } \mathrm{C}_{3} \mathrm{H}_{3} \mathrm{~N}_{2}-\mathrm{CH}_{2} \mathrm{CH}_{3}
\end{gathered}
$$




\section{RESULTS AND DISCUSSION}

Oxidation of essential amino acids by nicotinium dichromate has been studied in aqueous medium in presence of perchloric acid at $313 \mathrm{~K}$, under the pseudo-first order conditions and the observed results were discussed below.

\subsection{Effect of varying oxidant concentration}

Under pseudo-first order conditions of [amino acid] $>>$ [nicotinium dichromate] at constant [amino acid], $\left[\mathrm{HClO}_{4}\right]$ and temperature, plot of $\log [\mathrm{NDC}]$ versus time was linear indicating first order reaction and rate is depend on [NDC]. Furthermore, the rate constant did not change with change in concentration of nicotinium dichromate (Table 1), confirming first order dependence on (NDC).

\subsection{Effect of varying substrate concentration}

A plot of $\log \mathrm{k}_{1}$ versus $\log$ [substrate] $(\mathrm{r}=0.998)$ is linear with a slope less than unity (0.505) indicating fractional order dependence of rate on [substrate]. The plot of $1 / \mathrm{k}_{1}$ versus $1 /$ [substrate] is also linear $(\mathrm{r}=0.995)$ making an intercept on rate axis confirming fractional order dependence with respect to [substrate] (Table 1).

\subsection{Effect of varying perchloric acid concentration}

A plot of $\log \mathrm{k}_{1}$ versus $\log \left[\mathrm{H}^{+}\right](\mathrm{r}=0.999)$ is linear with a slope (1.98) confirming second order dependence with respect to [perchloric acid] (Table 1).

Table 1. Rate constant for the oxidation of essential amino acids by NDC at $313 \mathrm{~K}$ in aqueous medium in the presence of perchloric acid.

\begin{tabular}{|c|c|c|c|c|c|c|c|c|}
\hline \multirow{2}{*}{$\begin{array}{c}{[\mathrm{NDC}]} \\
10^{3} \\
\mathrm{~mol} \mathrm{dm}^{-3}\end{array}$} & \multirow{2}{*}{$\underset{\mathrm{mol} \mathrm{dm^{-3 }}}{[\text { Amino acid] }} \mathbf{1 0}^{2}$} & \multirow{2}{*}{ 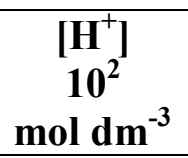 } & \multicolumn{6}{|c|}{$k_{1} 10^{4} s^{-1}$} \\
\hline & & & Val & Leu & Ile & Thr & Phe & His \\
\hline 6.0 & 2.0 & 5.0 & 4.34 & 4.46 & 5.67 & 2.71 & 4.14 & 9.25 \\
\hline 8.0 & 2.0 & 5.0 & 4.30 & 4.43 & 5.65 & 2.78 & 4.18 & 9.20 \\
\hline 10.0 & 2.0 & 5.0 & 4.37 & 4.40 & 5.60 & 2.74 & 4.10 & 9.29 \\
\hline 12.0 & 2.0 & 5.0 & 4.29 & 4.49 & 5.67 & 2.73 & 4.13 & 9.23 \\
\hline 14.0 & 2.0 & 5.0 & 4.30 & 4.46 & 5.61 & 2.78 & 4.19 & 9.27 \\
\hline 6.0 & 2.0 & 5.0 & 4.34 & 4.46 & 5.67 & 2.71 & 4.14 & 9.25 \\
\hline 6.0 & 3.0 & 5.0 & 5.32 & 5.45 & 6.95 & 3.11 & 5.01 & 11.2 \\
\hline 6.0 & 4.0 & 5.0 & 6.14 & 6.28 & 7.84 & 3.36 & 5.56 & 12.8 \\
\hline 6.0 & 5.0 & 5.0 & 6.88 & 7.04 & 8.67 & 3.86 & 6.04 & 14.7 \\
\hline 6.0 & 6.0 & 5.0 & 7.60 & 7.80 & 9.44 & 3.98 & 6.52 & 15.9 \\
\hline 6.0 & 2.0 & 5.0 & 4.34 & 4.46 & 5.67 & 2.71 & 4.14 & 9.25 \\
\hline 6.0 & 2.0 & 7.5 & 8.23 & 10.3 & 12.3 & 5.76 & 10.0 & 17.6 \\
\hline 6.0 & 2.0 & 10.0 & 15.16 & 17.8 & 21.1 & 12.7 & 17.5 & 30.0 \\
\hline 6.0 & 2.0 & 12.5 & 23.23 & 27.8 & 32.2 & 16.2 & 27.5 & 49.3 \\
\hline 6.0 & 2.0 & 15.0 & 30.99 & 38.7 & 47.8 & 22.8 & 38.4 & 87.0 \\
\hline
\end{tabular}




\subsection{Effect of varying ionic strength}

The change in ionic strength by the addition of sodium perchlorate has no effect on the rate constant (Table 2). This shows that the reaction may be between an ion and a neutral molecule (or) between neutral molecules.

\subsection{Effect of acrylonitrile}

To test for free radicals, the reaction mixture containing acrylonitrile was kept for $24 \mathrm{~h}$ in an inert atmosphere. On diluting the reaction mixture by methanol and no precipitate was observed. It is indicating that there is no intervention of free radicals in the reaction.

\subsection{Effect of varying manganous sulphate}

The reaction rate decreases with increasing the concentration of $\mathrm{Mn}^{2+}$ ion (Table 2) confirming the involvement of two electron process in this reaction [27].

Table 2. Effect of varying sodium perchlorate and manganous sulphate on the oxidation of amino acids by NDC at $313 \mathrm{~K}$.

\begin{tabular}{|c|c|c|c|c|c|c|c|}
\hline \multirow{2}{*}{$\begin{array}{c}{\left[\mathrm{NaClO}_{4}\right]} \\
10^{3} \\
\mathrm{~mol} \mathrm{dm}^{-3}\end{array}$} & \multirow{2}{*}{$\begin{array}{c}{\left[\mathrm{MnSO}_{4}\right]} \\
10^{3} \\
\mathrm{~mol} \mathrm{dm}^{-3}\end{array}$} & \multicolumn{6}{|c|}{$k_{1} 10^{4} s^{-1}$} \\
\hline & & Val & Leu & Ile & Thr & Phe & His \\
\hline 0.0 & 0.0 & 4.34 & 4.46 & 5.67 & 2.71 & 4.14 & 9.25 \\
\hline 1.0 & 0.0 & 4.28 & 4.69 & 5.65 & 2.79 & 4.11 & 9.29 \\
\hline 2.0 & 0.0 & 4.31 & 4.41 & 5.69 & 2.70 & 4.13 & 9.20 \\
\hline 3.0 & 0.0 & 4.39 & 4.46 & 5.63 & 2.72 & 4.17 & 9.29 \\
\hline 4.0 & 0.0 & 4.33 & 4.40 & 5.67 & 2.74 & 4.15 & 9.21 \\
\hline 0.0 & 0.0 & 4.34 & 4.46 & 5.67 & 2.71 & 4.14 & 9.25 \\
\hline 0.0 & 1.0 & 4.30 & 4.40 & 5.63 & 2.62 & 4.10 & 9.20 \\
\hline 0.0 & 2.0 & 4.21 & 4.37 & 5.58 & 2.40 & 4.02 & 9.13 \\
\hline 0.0 & 3.0 & 4.09 & 4.33 & 5.50 & 2.28 & 3.96 & 9.09 \\
\hline 0.0 & 4.0 & 3.88 & 4.29 & 5.38 & 2.15 & 3.88 & 9.00 \\
\hline
\end{tabular}

\subsection{Effect of Temperature}

The reaction was studied at different temperatures viz., 303,313,323 and $333 \mathrm{~K}$, keeping other experimental conditions. The rate constant of the reaction was found to increase with increasing temperature. From the Eyring's [28] plot of $\ln \mathrm{k}_{2} / \mathrm{T}$ versus $1 / \mathrm{T}$, activation energy and other thermodynamic parameters were calculated (Table 3). The negative values of the entropy of activation $\left(\Delta \mathrm{S}^{\#}\right)$ as expected for bimolecular reaction. The values of the free energy of activation $\left(\Delta \mathrm{G}^{\#}\right)$ were nearly constant indicating that a similar mechanism operated for the oxidation of all the essential amino acids studied. 
Table 3. Thermodynamic and activation parameters for the oxidation of essential amino acids by NDC.

\begin{tabular}{|c|c|c|c|c|c|c|c|c|}
\hline \multirow[b]{2}{*}{ Substrate } & \multicolumn{4}{|c|}{$k_{1} 10^{4} s^{-1}$} & \multirow{2}{*}{$\begin{array}{c}\Delta \mathbf{H}^{\#} \\
\mathbf{k J} \mathbf{m o l}^{-1}\end{array}$} & \multirow{2}{*}{$\begin{array}{c}-\Delta S^{\#} \\
\mathbf{J K}^{-1} \mathbf{m o l}^{-1}\end{array}$} & \multirow{2}{*}{$\begin{array}{c}\Delta G^{\#} \\
\mathrm{~kJ} \mathrm{~mol}^{-1} \\
\text { at } 313 \mathrm{~K}\end{array}$} & \multirow{2}{*}{$\begin{array}{c}\mathrm{E}_{\mathrm{a}} \\
\mathrm{kJ} \mathrm{mol}^{-1} \\
\text { at } 313 \mathrm{~K}\end{array}$} \\
\hline & $\begin{array}{c}303 \\
\text { K }\end{array}$ & $\begin{array}{c}313 \\
\text { K }\end{array}$ & $\begin{array}{c}323 \\
\text { K }\end{array}$ & $\begin{array}{c}\mathbf{3 3 3} \\
\text { K }\end{array}$ & & & & \\
\hline Val & 2.12 & 4.34 & 8.10 & 15.41 & 52.60 & 109.47 & 86.85 & 55.20 \\
\hline Leu & 2.29 & 4.46 & 8.22 & 15.52 & 50.65 & 115.29 & 86.74 & 53.25 \\
\hline Ile & 3.03 & 5.67 & 13.04 & 19.65 & 51.32 & 110.63 & 85.94 & 53.92 \\
\hline Thr & 1.30 & 2.71 & 5.36 & 8.92 & 51.62 & 116.49 & 88.08 & 54.22 \\
\hline Phe & 2.89 & 4.14 & 7.61 & 12.16 & 38.52 & 153.80 & 86.65 & 41.12 \\
\hline His & 3.86 & 9.25 & 19.22 & 40.71 & 62.92 & 70.30 & 84.93 & 65.52 \\
\hline
\end{tabular}

$[$ amino acid $]=2.0 \times 10^{-2} \mathrm{~mol} \mathrm{dm}^{-3} ;\left[\mathrm{H}^{+}\right]=5.0 \times 10^{-2} \mathrm{~mol} \mathrm{dm}^{-3} ;[\mathrm{NDC}]=6.0 \times 10^{-3} \mathrm{~mol} \mathrm{dm}^{-3}$

\section{MECHANISM AND RATE LAW}

It is clear that the reaction has first order with respect to NDC, fractional order with respect to amino acid and second order with respect to $\mathrm{H}^{+}$. The ionic strength of the medium had a negligible effect on the reaction rate, the added $\mathrm{Mn}^{2+}$ had a catalytic effect on the reaction rate and the absence of free radicals during the course of the reaction. The observed data can be explained on the basis of the following mechanism.

$$
\begin{aligned}
& \mathrm{NDC}+\mathrm{H}^{+} \stackrel{K_{1}}{\rightleftharpoons} \mathrm{NDCH}^{+} \\
& \mathrm{S}+\mathrm{H}^{+} \rightleftharpoons \stackrel{K_{2}}{\rightleftharpoons} \mathrm{SH}^{+} \\
& K_{3} \\
& \left.\mathrm{NDCH}^{+}+\mathrm{SH}^{+} \underset{\text { slow }}{\longrightarrow} \text { [complex }\right] \\
& {[\text { complex }] \stackrel{K_{4}}{\text { fast }} \mathrm{HCHO}+\mathrm{Cr}(\mathrm{IV})}
\end{aligned}
$$

The above mechanism leads to the following rate law:

$$
\begin{aligned}
& \text { rate }=k_{3}[\text { Complex }] \\
& =\frac{K_{2} k_{3}\left[S H^{+}\right]\left[H^{+}\right]}{1+K_{2}[S]}
\end{aligned}
$$




$$
=\frac{K_{1} K_{2} k_{3}[N D C][S]\left[H^{+}\right]^{2}}{1+K_{2}[S]}
$$

Equation (6) accounts for first order dependence on [NDC], second order dependence on $\left[\mathrm{HClO}_{4}\right]$ and fractional order dependence on [amino acid]. Equation (4) indicates the involvement of a two-electrons reduction of $\mathrm{Cr}$ (VI) to $\mathrm{Cr}$ (IV) which is confirmed by the decrease in the rate constant with the addition of manganous sulphate (Table 2).

\section{CONCLUSION}

The oxidation of essential amino acids by NDC in aqueous medium in the presence of perchloric acid leads to the formation of a complex giving corresponding aldehyde as the final product. The reaction follows pseudo-first order kinetics. Increase in temperature increases the rate of the reaction. The activation parameters are evaluated from the study of oxidation at different temperatures. The mechanism proposed for this oxidation kinetics is in accordance with the observed kinetic facts. The negative sign of the entropy change suggests that the transition state is more orderly when compared with the reactants.

\section{Acknowledgement} provided.

The authors thank the Management, National College (Autonomous), Tiruchirappalli, for the facilities

\section{References}

[1] K.B.Wiberg, Oxidation in Organic Chemisry, Academic press, Newyork, (1965)

[2] B. Bhattacharjee, M. N. Bhattacharjee, M. Bhattacharjee, A. K. Bhattacharjee, Bull Chem. Soc.Jpn., 59 (1986) 3217-3221

[3] Irona Nongkynrih, Mahendra K.Mahanti, J. Org. Chem. 58 (1993) 4925-4928

[4] Jari T.Yli-Kauhaluoma, Curtis W,Harwig, Paul Wentworth Jr, Kim D.Janda, Tetrahedron Lett. 39 (1998) 2269-2272

[5] S.G.Patil, S.B.Joshi, Asian J. Chem. 14(1) (2002) 130-134

[6] Hesham A.A.Medien, Z.Naturforsch. 58b (2003) 1201-1205

[7] K.G.Sekar, Int.J. Chem. Sci. 1 (3) (2003) 227-232

[8] S.S.Mansoor, S.S.Shafi, J. Mol. Liq. 155 (2010) 85-90

[9] Pravesh Kumar, Dinesh Panday, Seema Kothari, Croat. Chem. Acta. 84(1) (2011) 53-61

[10] Dipti, A.Tomar, A.Kumar, Oxid. Commun. 35(3) (2012) 569-576

[11] K.G.Sekar, S.K.Periyasamy, International Letters of Chemistry, Physics and Astronomy 5 (2012) 8-19

[12] K.G.Sekar, G.Manikandan, Oxid. Commun. 35(3) (2012) 577-582 
[13] S.Zaheer Ahmed, S.Syed shafi, S.Sheik Mansoor, Adv. Appl. Sci. Res. 3(1), (2012) $123-$ 129

[14] Bhupendra AMB, B.L.Hiran, Oxid. Commun. 35(3) (2012) 560-568

[15] Seema Panwar, Shilpa pohani, Peeeti swami, Shweta vyas, Pradeep k.Sharma, Euro. Chem. Bull. 2(11) (2013) 904-909

[16] Chockalingam Karunakaran, Vaithiyalingam Chidambaranathan, Creat. Chem. Acta 74(1) (2001) 51-59

[17] D.S.Bhuvaneshwari, K.P.Elango, Int. J. Chem. Kinet. 38 (2006) 657-665

[18] A.N.Palaniappan, A.Arulmozhi varman, S.Srinivasan, S.Senthilkumar, J. Chem. Pharm. Res. 4(6) (2012) 2874-2878

[19] Puttaswamy, Nirmala vaz, Indian Acad. Sci. (Chem. Sci), 113 (4) (2001) 325-332

[20] K.Vivekanandan, Oxid. Commun. 27(1) (2004) 195-202

[21] Ragavendra Shukla, Pradeep K.Sharma, Kalyan K.Banerji, J. Chem. Sci. 116(2) (2004) 101-106

[22] Dimple Garg, Seema Kothari, Indian J. Chem. 44B (2005) 1909-1914

[23] L.Pushpalatha, K.Vivekanandan, Oxid. Commun. 33(4) (2010) 851-863

[24] A. Sharma, A.Meena, J.Khatri, P.Swami, Vinita Sharma, J. Appl. Chem. 1(1) (2012) 7078

[25] C.Lopez, A.Gonzalex, F.P.Cossio, C.Palomo, Synth. Commun. 15(13) (1985) $1197-$ 1211

[26] K.Vivekanandan, R.Lakshmi Narayanan, Oxid. Commun. 37(3) (2014) 662-668

[27] K.B.Wiberg, Th.Mill, J. Am. Chem. Soc. 80 (12) (1958) 3022

[28] A.A.Frost, R.G.Pearson, Kinetics and Mechanism, Wiley Eastern, New Delhi, (1970) 